\title{
NOWCASTING UKRAINE'S GDP USING A FACTOR-AUGMENTED VAR (FAVAR) MODEL
}

\section{Anton Grui}

National Bank of Ukraine

E-mail: Anton.Grui@bank.gov.ua
Roman Lysenko

National Bank of Ukraine

E-mail: Roman.Lysenko@bank.gov.ua

\section{ABSTRACT}

This article presents an approach for nowcasting the current value of Ukraine's quarterly GDP. The approach uses leading indicators with a different disclosure frequency. We generalize data from a set of explanatory variables into several factors by using principal components analysis and estimate the factor-augmented VAR (FAVAR) model. Our system incorporates new data as they are published throughout a quarter to adjust GDP nowcasts. In addition, we research the influence of separate data releases on the accuracy of forecasts.

\section{JEL Codes: C53, C82, E17}

Keywords: principal components, nowcasting, factor model

\section{INTRODUCTION}

Where is the economy heading and what is the current rate of economic growth? Real quarterly GDP is one of the best indicators of an economy's course and growth rate. However, GDP is reported well after the end of a quarter, while decisions on economic policy require real-time information about the current state of the economy. International practice has shown it possible to obtain that information through so-called nowcasting models that allow an assessment of the state of an economy before official data is disclosed.

Nowcasting refers to the forecasting of data for the current time period. The central banks of most advanced economies use nowcasting. Given the time lag between changes to monetary policy and their effect on the economy, central banks need early readings of the current economic situation. Among other things, the timely detection of economic shifts is needed to achieve and maintain price stability.

In macroeconomic forecasting, there may be a large number of possible explanatory variables. Factor analysis makes it possible to distinguish the main drivers of variation within a set of variables. Thus, a lower number of estimated factors can summarize a sizable amount of information from a large system.

Factor-augmented (factor) models carry numerous advantages. First, they can cover many variables to avoid the problem of a lack of degrees of freedom. Moreover, incorporating a large amount of information helps to yield more accurate estimates for forecasting and macroeconomic analysis. Second, factor analysis can discard a variable's own shocks that have no impact on overall trends within a system. Those shocks may include errors of measurement. In this way, monetary policy receives a reliable signal from the economy and is not compelled to react to noise. In addition, distinguishing general economic factors and shocks is an important task in macroeconomic analysis. Third, factor models remain agnostic about an economy's structure and are not dependent on economic assumptions.

This article develops and investigates the forecasting performance of a factor model for nowcasting Ukraine's GDP. This type of model should be based on accessible leading indicators and should make use of information as new data is released. Forecasting performance is assessed using experiments on pseudo out-of-sample forecasting. We simulate a real situation with limited time spans of data available for estimating factors and equation coefficients. The model is capable of re-estimating the factors and coefficients as new data becomes available and to gradually adjust GDP nowcasts. However, the design of these types of experiments differs from the ideal one, because it uses the latest available data. Some historical data might have been reviewed post factum.

This article is built as follows: section 2 contains an overview of literature; section 3 analyzes Ukraine's GDP dynamics over the past 10 years; section 4 describes the data and the factors built on the basis of the data, provides an economic background for the factors, and presents their relationship to GDP dynamics; section 5 presents the nowcasting model, provides a timeline of the relevant new data releases, provides a simulation of the quarterly nowcasting procedure, and analyzes forecast errors; and section 6 concludes. 


\section{LITERATURE OVERVIEW}

Using estimated factors as regressors to nowcast year-on-year GDP growth is the key topic of this research. The factors are calculated using a large set of variables.

Let $X_{t}=\left[x_{1 t}, \ldots, x_{N t}\right] '$ - be a vector of $\mathrm{N}$ observed time series describing the economy. Each of its elements can be presented as

$$
x_{i t}=\lambda_{i 1} f_{1 t}+\ldots+\lambda_{i R} f_{R t}+u_{i t}
$$

or in matrix form

$$
X_{t}=\Lambda F_{t}+U_{t^{\prime}}
$$

where $U_{t}=\left[u_{1 t^{\prime}} \ldots, u_{N t}\right]^{\prime}-$ represents the vector of the own shocks of observed variables, $F_{t}=\left[f_{1 t^{\prime}} \ldots, f_{R t}\right]^{\prime}-$ represents the vector consisting of $\mathrm{R}$ unobserved common factors, and $\Lambda=\left[\begin{array}{ccc}\lambda_{11} & \cdots & \lambda_{1 R} \\ \vdots & \ddots & \vdots \\ \lambda_{R 1} & \cdots & \lambda_{N R}\end{array}\right]$ represents the matrix of loadings.

Breitung and Eickmeier (2006) estimate a matrix of loadings using Principal Component Analysis (PCA). Section 2 in the above paper describes the technical aspect of this tool. The factors $F_{t}$ calculated using PCA are orthogonal and are called principal components.

Factor models are used in building economic indicators, analyzing economic policy, and forecasting.

The Chicago Fed National Activity Index (CF-NAI) and EuroCOIN are among the most famous economic indicators. The CF-NAI is calculated as the first principal component of a series of economic activity indicators in the United States. The index was developed by Stock and Watson (1999) and found to be useful when forecasting inflation. In the more current paper by Brave and Butters (2014), the index is used to nowcast GDP. EuroCOIN is a common component of euro area countries' GDP. The index was proposed by Altissimo et al. (2001). Similarly, Cristadoro et al. (2001) construct a measure of core inflation for the euro area, while Kapetanios (2004) does so for the United Kingdom.

Forni et al. (2004) and Giannone et al. (2004) use factor analysis to detect structural shocks that form the common dynamics of economic variables, and discuss the constructive feedback from monetary policy. Moreover, Taylor's rule with estimated factors included is more sustainable and reliable monetary policy rule.

Bernanke et al. (2005) study the effect of the interest rate on the economy using factor augmented VAR (FAVAR) models. VAR models provide a consistent analytical approach. However, they are vulnerable to the problem of a lack of degrees of freedom. It is natural to build models based on estimated factors that effectively generalize information from many macroeconomic variables. Below is the resulting specification:

$$
\left[\begin{array}{l}
F_{t} \\
i_{t}^{t}
\end{array}\right]=\Phi(L)\left[\begin{array}{c}
F_{t-1} \\
i_{t-1}
\end{array}\right]+\vartheta_{t^{\prime}}
$$

where $\vartheta_{t}$ is white noise, $F_{t}$ is the vector of factors estimated via PCA, $\Phi(L)$ is the lag polynomial, and $i_{t}$ is the federal funds interest rate.

Gupta et al. (2010) use a similar specification to assess the effect of defense spending on the U.S. output.

Factor models are used widely as a forecasting tool. Stock and Watson (1999) study inflation forecasting using the Phillips curve, while replacing the unemployment rate with an estimated index of U.S. business activity. The ability of that type of factor model to yield out-of-sample forecasts exceeds the ability of univariate methods or of the simple Phillips curve. Stock and Watson (2002) use first principal components to forecast industrial production in the short-run. Given the ability to forecast both inflation and real values, Bernanke and Boivin (2003) suggest including factors in the function of the monetary policy reaction.

Forni et al. (2005) forecast inflation and industrial production for the euro area, Brisson et al. (2003) - some real values for Canada, and Artis et al. (2005) - for the United Kingdom. Projected variables are usually defined as functions of their own current and previous values and of current and previous values of estimated factors.

Stock and Watson (2006) scrutinize the approach of Bernanke et al. (2005) and suggest that FAVAR can be used for forecasting. Itkonen (2016) describes the use of that style of model to nowcast Finland's GDP.

In general, the forecast parameters of factor models are encouraging. They outclass univariate methods and models with fewer variables. However, it should be noted that the choice of a set of variables for the analysis is often random. At the 
same time, the same set can be used to forecast different values. Bovin and $\mathrm{Ng}(2005)$ suggest using only variables with high explanatory power in relation to the value being forecast.

The forecasting procedure is usually conducted in two steps. The first is to estimate several unobserved factors from a large set of variables. The PCA is conventionally used, and we use it in our paper. Some papers, including Giannone et al. (2008) and Porshakov et al. (2015), use the Kalman filter to estimate and recursively forecast factors. The second step is to use the estimated factors as explanatory variables to build a linear forecast model. Bańbura and Rünstler (2011) and Angelini et al. (2011) show that the Kalman filter can take both steps simultaneously.

In this paper, we construct and adjust nowcasts for quarterly real GDP growth in annual terms using leading indicators. By "leading indicators", we refer to indicators for which new data gradually appear over the course of a quarter.

This type of nowcasting model must combine monthly leading indicators with quarterly ones. In addition, it must work with ragged edges - observations for certain variables may be missing at the end of a sample. These types of models are called bridge equations, as they form bridges between observations with different frequencies.

The use of bridge equations is explored by Angelini et al. (2011). The authors simulate nowcasting euro-area GDP in pseudo real time using successive releases of monthly data. The Kalman filter copes with ragged edges and combines individual indicators into factors, while incorporating multidimensional information to forecast missing observations. This approach was first proposed by Giannone et al. (2006). Univariate methods are a more typical approach to forecasting missing observations of explanatory variables. In particular, in our study we rely on a random walk process.

Angelini et al. (2011) incorporate new data twice a month, which allows them to gradually improve a model's forecasting performance. Survey data carry considerable explanatory force as they provide information with a shorter delay than do indices of economic activity. Researchers have also found that bridge equations with factors have better forecasting performance than forecast averages of bridge equations with separate explanatory variables.

Bragoli et al. (2014) incorporate daily data releases from various sources to update nowcasts of Brazil's GDP, a noteworthy approach.

\section{HISTORICAL DYNAMICS OF UKRAINE'S GDP}

Ukraine's real GDP dynamics is notable for its substantial volatility. A time series of rates of change of Ukraine's quarterly real GDP in annual terms from 2006 to 2017 includes two crisis periods (2008-2009 and 2014-2015), during which GDP fell materially (by -19.6\% in Q1 2009 and -15.5\% in Q1 2015) (see Figure 1).

Figure 1. Real GDP

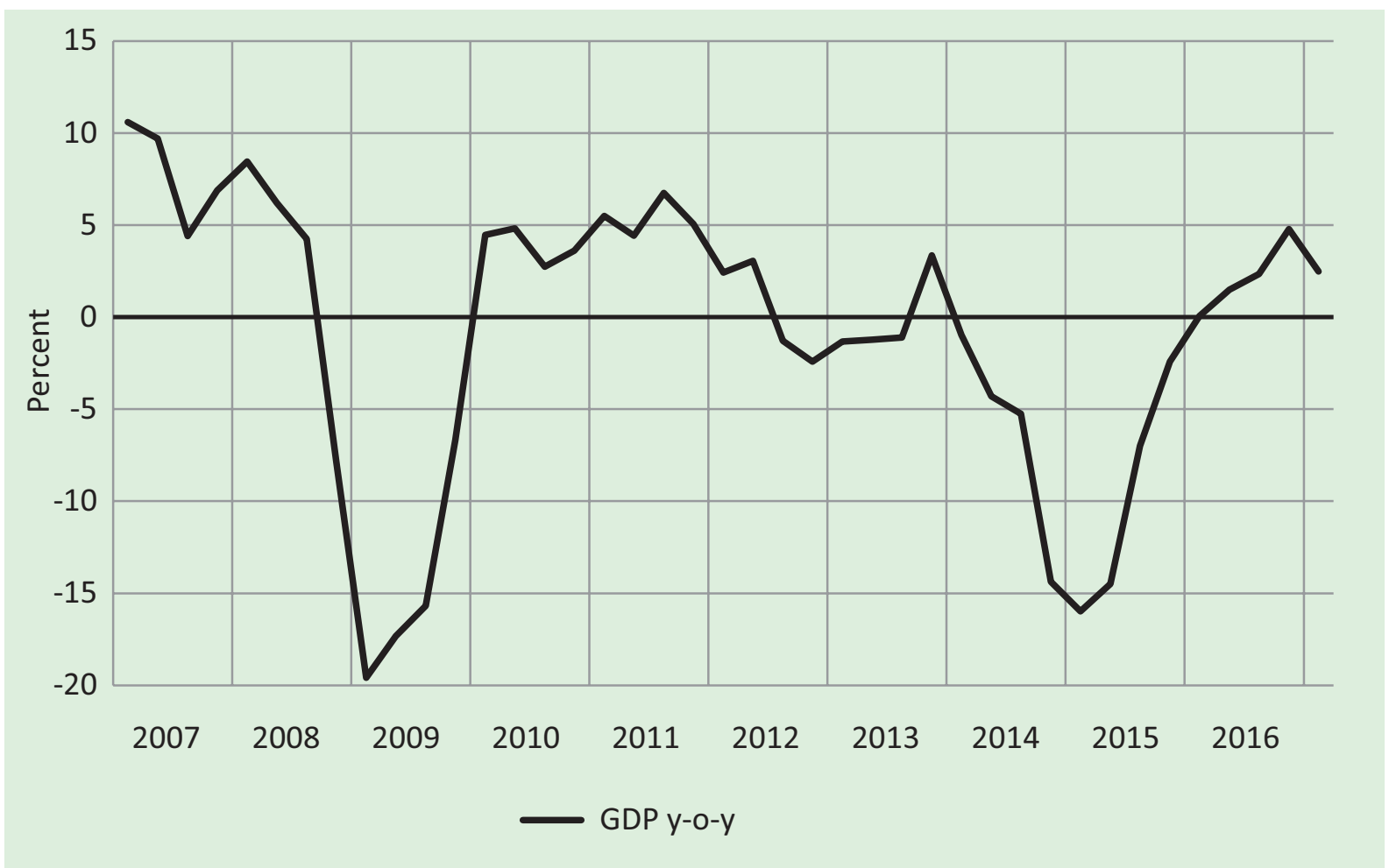


The sharp fall of Ukraine's real GDP from 2008 to 2009 was caused by capital flight related to the global financial and economic crisis. Commodity markets also deteriorated at that time. Commodities account for a large part of Ukraine's foreign trade, and the market turmoil caused a decline in the output of key export-oriented industries. In addition, business activity was affected by the realization of risks accumulated in the banking sector after the overheating of the real estate market from 2007 to 2008. That overheating manifested itself in the form of a credit boom, including in foreign currency debt.

A slow recovery of the global economy after the 2007-2009 crisis resulted into a weak recovery of Ukraine's economic growth. From 2010 to 2013, the average growth of real GDP came in at $2.5 \%$.

In Q4 2014, real GDP fell by $14.4 \%$ y-o-y. That resulted from geopolitical and economic shocks, including Russia's annexation of Crimea in March and the escalation of the military conflict in eastern Ukraine in August and September 2014. The breakdown of production and logistical ties between the government-controlled and non-government controlled areas caused a steep drop in industrial production and exports.

Since 2016, the Ukrainian economy has been recovering, but growth remains unstable. Ukraine's GDP growth is affected by external factors because the foreign trade of the country remains reliant on raw materials and because of the continuing military conflict in eastern Ukraine.

Consequently, the causes of crises in the Ukrainian economy differ. They are hard to predict using only models based on economic theory. Ukraine is a small open economy, which continues to be affected by external factors. Therefore, even under conditions of relative stability, forecasting current economic activity is not a straightforward task.

\section{DATA AND ASSESSED FACTORS}

The dataset we use to build unobservable factors includes 20 indicators. Among them:

- indices of key sector output ${ }^{1}$ (IKSO) (industry, agriculture, construction, trade and transport, expressed as the annual growth in real production - nine indicators in all, published monthly);

- business outlook surveys ${ }^{2}$ (assessments of financial and economic standing, expectations of sales and investment etc., as the annual change in the balance of positive and negative replies - a total of 11 indicators, published quarterly).

Monthly data are converted into quarterly data by taking the arithmetic mean for the three months of the quarter. Missing observations are projected using the random-walk process. Our study contains some fewer indicators than other studies. However, all the indicators have explanatory power for estimating GDP. This model retains the advantages of factor models.

Below we consider the factors we built for all explanatory variables based on available data up to and including Q2 2017.

We use factors (principal components) to generalize changes in all available observable variables by using principal component analysis. Table 1 shows the correlation matrix between the variables (rows) and the top three principal components (columns). Each coefficient, if squared, determines the variation percentage for each variable explained by the relevant factor. Therefore, the sum of the coefficient squares in the row opposite each variable determines the variation percentage of this variable explained by the top three principal components. In contrast, the sum of the coefficient squares in the column opposite each factor divided by the total number of variables shows the variation percentage for the entire system that is explained by that factor.

Estimated principal components serve as estimates of the unobservable key economic shocks' realizations. However, these components do not necessarily allow a direct structural interpretation since they can be linear combinations of real economic factors.

The first principal component is a generalized indicator for the country's economic activity since it determines both growth in key sector output and positive change in the business outlook. In addition, it explains $57 \%$ of all variation in the system. Most variables have a significant positive correlation with the component (0.46-0.95), except:

- the index of agricultural output, a volatile indicator that does not correlate with the growth in the output of other industries. However, this index depends heavily on the second and the third components;

- current stocks of finished goods, an indicator that is negatively correlated with an increase in demand, but positively correlated with agricultural output. Once again, the second and the third components have a decisive influence on the indicator. 
Table 1. Correlation Matrix

\begin{tabular}{|c|c|c|c|c|}
\hline & PC1 & PC2 & PC3 & $\begin{array}{c}\text { Explained } \\
\text { variation }\end{array}$ \\
\hline Agriculture & -0.06 & 0.41 & 0.61 & 0.54 \\
\hline Mining industry & 0.80 & 0.22 & 0.40 & 0.85 \\
\hline Manufacturing industry & 0.95 & 0.13 & -0.03 & 0.92 \\
\hline Production of electric power, gas and water & 0.84 & 0.04 & 0.31 & 0.80 \\
\hline Construction & 0.79 & 0.45 & -0.09 & 0.84 \\
\hline Retail trade & 0.60 & 0.70 & -0.02 & 0.85 \\
\hline Wholesale trade & 0.87 & 0.24 & 0.07 & 0.81 \\
\hline Freight transport & 0.88 & -0.04 & 0.17 & 0.81 \\
\hline Passenger transport & 0.59 & 0.62 & -0.35 & 0.86 \\
\hline Current financial and economic standing & 0.90 & 0.01 & -0.20 & 0.86 \\
\hline Financial and economic standing expected in the next 12 months & 0.85 & -0.41 & 0.17 & 0.92 \\
\hline Change in sales expected in the next 12 months & 0.87 & -0.28 & 0.11 & 0.85 \\
\hline Change in export sales expected in the next 12 months & 0.78 & -0.33 & 0.10 & 0.73 \\
\hline Current stocks of finished goods & -0.37 & 0.65 & 0.35 & 0.69 \\
\hline Current ability to meet an unexpected increase in demand & 0.56 & -0.02 & -0.25 & 0.37 \\
\hline Investment change expected in the next 12 months & 0.91 & -0.29 & 0.00 & 0.91 \\
\hline Staff level change expected in next 12 months & 0.91 & -0.35 & 0.06 & 0.95 \\
\hline Borrowing needs expected in the next 12 months & 0.46 & -0.30 & -0.36 & 0.43 \\
\hline Current availability of Ioan & 0.86 & -0.10 & 0.03 & 0.76 \\
\hline Intentions to take out loans in the near term & 0.48 & 0.59 & -0.45 & 0.79 \\
\hline Explained variation & 0.57 & 0.14 & 0.07 & \\
\hline
\end{tabular}

The second main component is an indicator of opposite shifts in business sentiment (negatively correlated, except intentions to take out bank loans) and the actual output of key sectors (positively correlated, including with current stocks of finished goods). The second component determines $14 \%$ of the variation in the set of variables.

The third principal component is difficult to interpret. We observe positive or insignificant correlations with the indices of output for key sectors, but not with passenger transportation. This component is negatively correlated with assessments of current financial and economic standing, the ability to meet a sudden increase in demand, future borrowing needs, and the intention to take out loans. In contrast, positive correlations are observed with the current stocks of finished goods and expectations of future financial and economic standing, sales, investment, or the number of employees. The third component explains $7 \%$ of the total variation.

The fourth and subsequent components are not used in this study as they explain only a small percentage of aggregate dynamics in total inputs. We have set a peculiar threshold value at $5 \%$ of the total variation, which is the mean across all 20 possible principle components. This approach was first proposed by Kaiser in 1960 . That approach is not necessarily suitable for choosing the number of variables to be used in a VAR model. However, we have empirically determined that using additional principal components does not improve the model's forecasting performance.

The annual change in GDP and the top three principal components are shown in Figure 2. The dramatic decline and recovery in GDP that occurred in 2008 and 2009 were accompanied by significant negative values in the first component, with the second and third component having higher values. In contrast, all three components were negative when GDP dropped in 2014 and 2015. The first component has persistently had high values since the beginning of 2016, which can be a sign of an economic recovery in Ukraine. However, the volatile factors that are responsible for the second and third component continue to restrain the recovery. 
Figure 2. Real GDP and Main Components

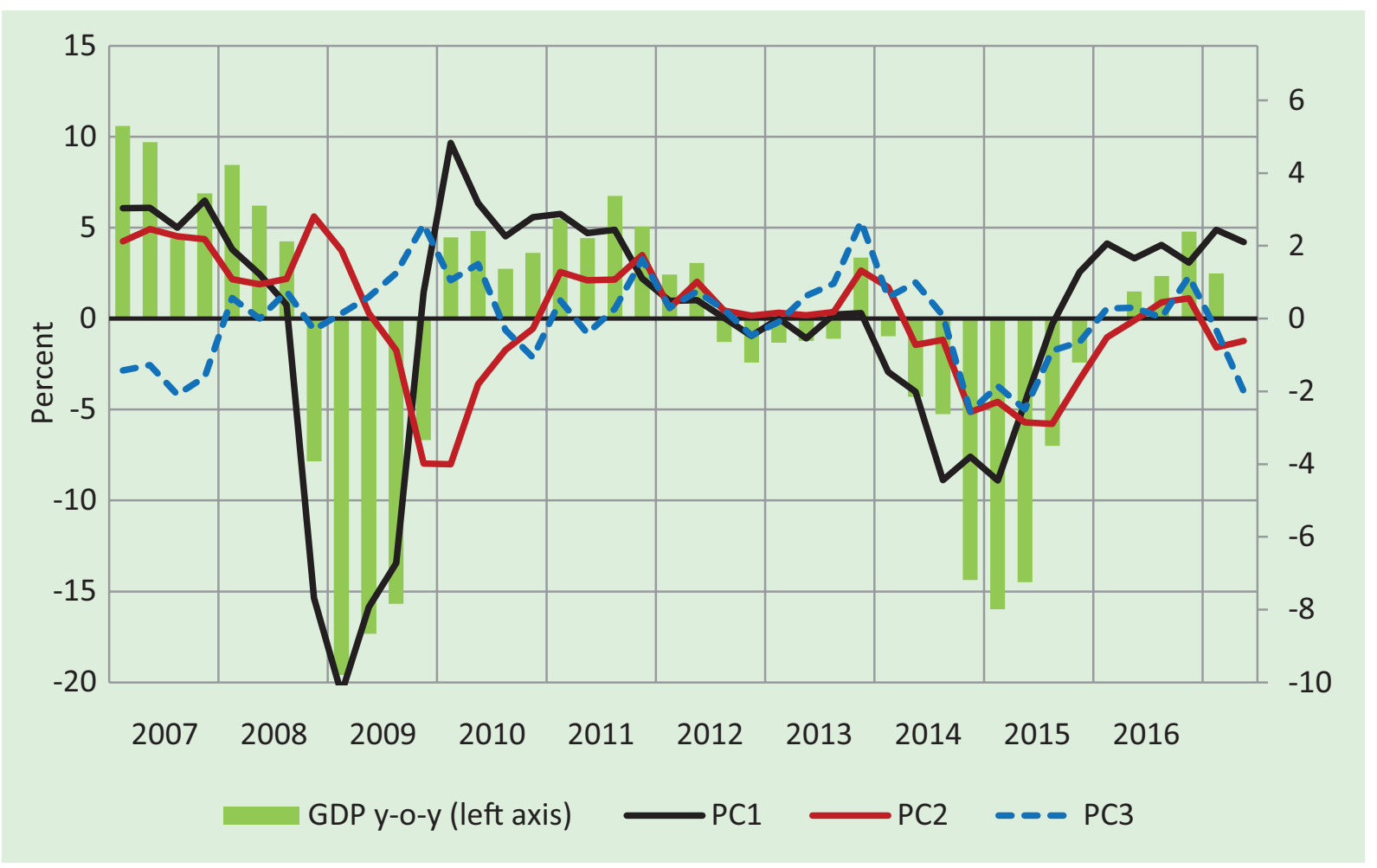

\section{NOWCASTING UKRAINE'S GDP}

Nowcasting the year-over-year change in quarterly real GDP is done based on a relatively large number of explanatory variables represented by leading indicators. The use of a factor-augmented VAR model (FAVAR model) is as follows:

$$
\left[\begin{array}{c}
y_{t} \\
F_{t+1}
\end{array}\right]=\Phi(L)\left[\begin{array}{c}
y_{t-1} \\
F_{t}
\end{array}\right]+\varepsilon_{t^{\prime}}
$$

where $y_{t}$ represents annual GDP growth. The factors $F_{t}$ are shifted forward by one quarter to incorporate the most recent data for the input variables that is made public before the official GDP reading is published.

The final version of the model builds a relationship with only one lag. Effectively, the estimation of current GDP growth is simplified to the indicator's linear dependence on its previous value and the values of the factors for the current quarter. VAR forecasting takes place when no data for the target quarter and GDP readings for the previous quarter are available.

All the relevant information to estimate GDP under our specification includes business outlook survey findings, output for key sectors for three months, and GDP estimates for the previous quarter. Those data are made public at different times. The third month of output data for key sectors appears last, approximately on the 23rd day after the end of a target quarter. This enables backcasting on the basis of a full set of inputs. Backcasting can be useful since the State Statistics Office provides preliminary estimates only on the 45th day after the end of a reporting quarter.

Economic policy, however, requires real-time estimates. The first nowcasts for change in GDP in the current quarter can be made at the beginning of the quarter. On day zero of quarter $t$, we have business outlook survey results for quarter $t-1$ and IKSO growth for the first two months of quarter t-1. IKSO component data for the three months of t-1 come out on the 23 rd day. Thus, all the relevant information gradually becomes available over the course of 113 days after the start of the target quarter. Figure 3 shows an approximate schedule for the release of new data. 
Figure 3. Publishing Schedule for Relevant Inputs

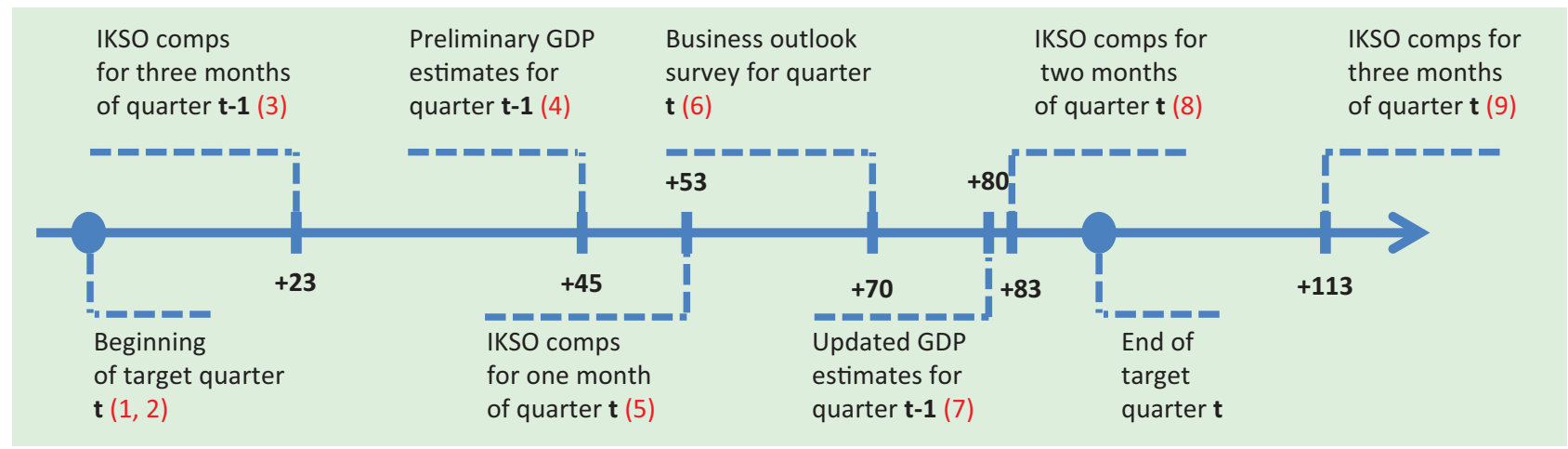

The earliest data for the target quarter are released on the 53rd day when IKSO growth data for month one are published. Up to that point, current economic activity is estimated based on data from the previous quarter.

Assessing the quality of forecasts is essential for building and applying forecast models. To that end, we compare forecasts to actual data, with the difference between the two being the forecast error. Although the root mean square error (RMSE) is the most frequently used measure of a model's quality, this measure overestimates the values of errors in our simulations due to the structural changes that occurred in 2014 and 2015. That is why we use the mean absolute error (MAE).

We also revise the nowcasts each time new relevant information becomes available. It is thus important to know what data were available when a particular forecast was made. To estimate the forecasting performance of models we use pseudo-outof-sample forecasting. Estimates are made for the period from Q1 2012 through Q1 2017. More specifically, we use a total of 21 observations to determine the forecasting performance of various models and specifications. Figure 4 shows the first forecast that becomes available at the beginning of the target quarter and the last forecast that becomes available on the $23 \mathrm{rd}$ day after the end of the target quarter.

Model parameters are estimated based on the historical period that precedes the forecast period. That is why the parameters are revised each time this period is extended - just as would have been done in the case of a real time forecast.

\section{Figure 4. The Forecasting Performance of the First and Last Iterations of a FAVAR Model}

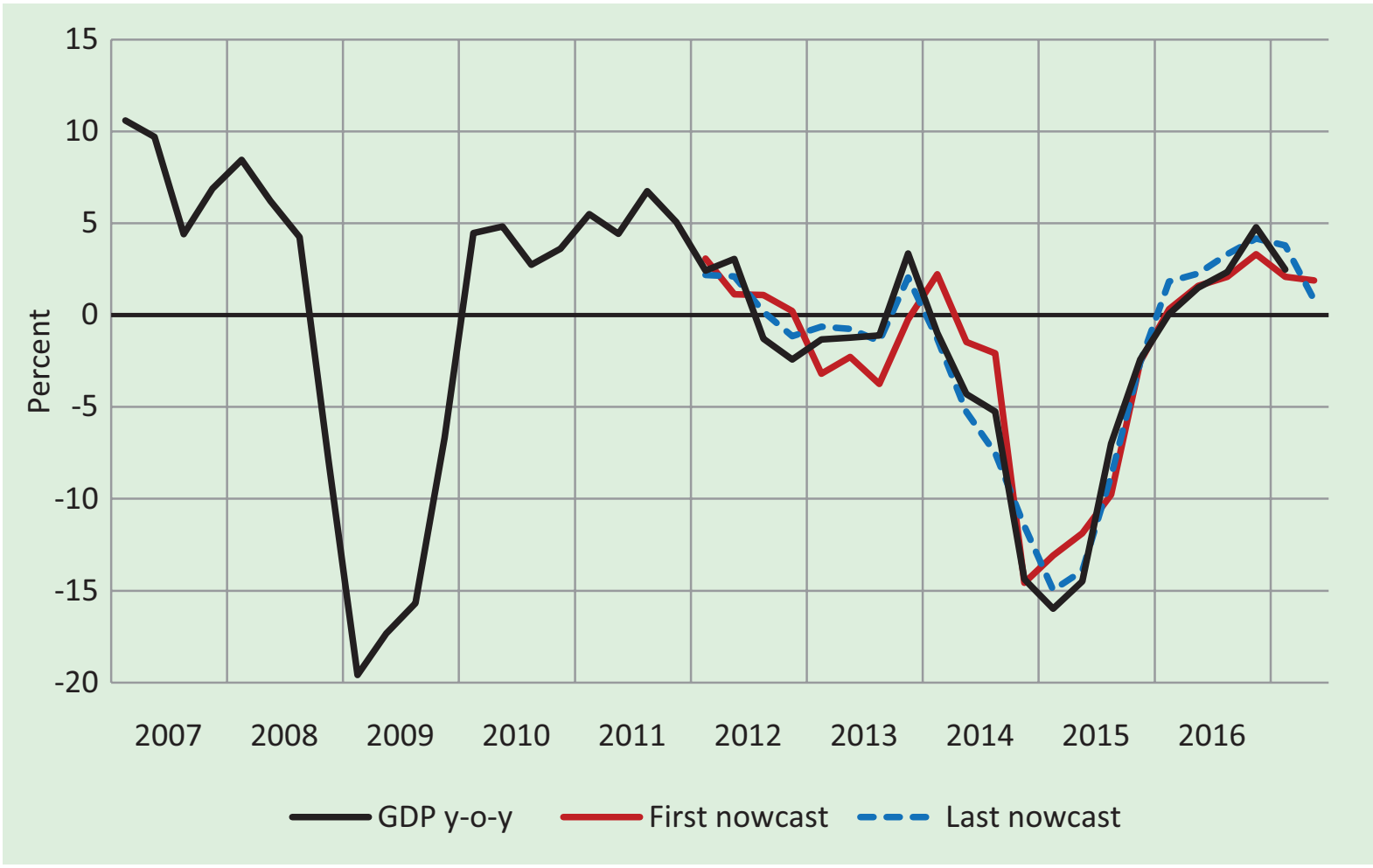


The forecasting performance of the last nowcast is reasonably high both in the relatively stable 2012-2013 and in 2014-2015 when structural changes occurred. The quality of the first nowcast is poorer - among other things, it failed to predict the drop in GDP in 2014 in time. However, it was reasonably accurate in simulating the general downward trend and the subsequent recovery in 2016.

Overall, the forecasting performance of FAVAR models gradually improves as new data become available (Table 2). A nowcast that is produced on day zero of the target quarter may incorporate findings of the business outlook survey for the previous quarter, or it may disregard such findings (iteration (1) and (2)). It appears that predictions that did not rely on these findings were more accurate. This suggests that businesses are not very good at predicting economic activity beyond the current quarter. Figure 4 specifically reports forecasts that do not draw on survey findings.

\section{Table 2. Comparisons of Mean Absolute Errors in Forecasts Produced based} on the FAVAR and Alternative Models

\begin{tabular}{|c|c|c|c|c|c|c|c|c|c|}
\hline Days & 0 & 0 & 23 & 45 & 53 & 70 & 80 & 83 & 113 \\
\hline Iterations & (1) & (2) & (3) & (4) & (5) & (6) & (7) & (8) & (9) \\
\hline FAVAR & 2.15 & 1.76 & 1.56 & 1.56 & 1.88 & 1.36 & 1.31 & 1.14 & 1.05 \\
\hline Random walk & & 4.61 & & & 2.78 & & & 2.73 & \\
\hline Business Expectations Index & & & & & & \multicolumn{4}{|c|}{2.60} \\
\hline $\begin{array}{l}\text { Adjustments made by } \\
\text { Ukraine's State Statistics Office }\end{array}$ & & & & & 0.37 & & & & \\
\hline
\end{tabular}

Ukraine's State Statistics Office releases preliminary estimates for the change in GDP on the 45th day of the following quarter. These data are later adjusted on the 80th day. The mean absolute correction in the studied period is $0.37 \mathrm{pp}$, which is the lower boundary of the model's forecast error. This means that even an ideal forecast of preliminary estimates is not free from errors if compared to the revised data.

The upper boundary in our study is the error of the random walk forecast, in which each subsequent value is forecasted to be equal to the previous one. Up to the 45th day, the random walk forecast is growth in the quarter that precedes the last quarter; up to the 80th day, it is preliminary estimates; and after the 80th day, it is revised estimates for the last quarter. The values of mean average errors are reasonably high, which is attributed to the sharp drop in GDP that took place during the study period. The simulations of pseudo-out-of-sample forecasts show that the capabilities of our FAVAR model significantly exceed those of the random walk model.

The errors of the FAVAR nowcasts decrease with the published data on the rate of IKSO change for the third month of the previous quarter (iteration (3)). However, these errors increase after accounting for the rate of IKSO change for the first month of the current quarter (iteration (5)). This shows that data for the first month of a quarter usually do not reflect the change for the entire quarter. Accounting for the results of the business outlook survey for the current quarter (iteration (6)) significantly improves the forecasting performance of the model.

The Business Expectation Index (BEI), which is described in Lysenko and Kolesnichenko (2016), is calculated only based on the findings of the business outlook survey. Since this index can also be used as an explanatory variable when making short-term GDP estimates, we included the model for estimating short-term GDP that appeared in the above study (Table 5, column 3). It appears that the forecasting performance of our FAVAR model are higher than those of the model that relies on the BEI alone.

\section{CONCLUSION}

This paper aims to develop a factor model to nowcast Ukraine's GDP and to study its forecasting performance. The FAVAR model described in the paper is based on leading indices of output across key sectors and the findings of business outlook surveys. The model can be used for the intended purpose. Using the model for pseudo-real-time nowcasting shows that the model's forecasting performance exceed those of a random walk model and the forecasts that rely on business outlook survey findings alone.

We study the publishing schedule for relevant inputs and propose a timeline for revising current GDP estimates. This paper found that the overall accuracy of nowcasts improves as more data become available. More specifically, accounting for business outlook survey findings proved important in decreasing the error of current GDP estimates. At the same time, the survey findings failed to increase the accuracy of forecasts beyond the current quarter.

The paper also describes factors that were generated from a relatively large set of variables, using principal component analysis. The first component explains $57 \%$ of the total system variation, and can be interpreted as the index of total business activity. Follow-up studies can focus on a more detailed analysis of this and other components, as well as the economic factors on which the components are based. A separate study should deal with the implications that generalized factors yield for monetary policy. 
Potential areas for additional study in the area of nowcasting Ukrainian GDP and other real variables include expanding the list of explanatory variables and applying the Kalman filter.

\section{References}

- Altissimo F., Bassanetti A., Cristadoro R., Forni M., Hallin M., Lippi M., Veronese G. (2001). EuroCoIN: A Real Time Coincident Indicator of the Euro Area Business Cycle. Discussion Papers, No. 3108, CEPR.

- Angelini E., Camba-Mendez G., Giannone D., Reichlin L., Rünstler G. (2011). Short-term forecasts of euro area GDP growth. Econometrics Journal, Vol. 14, No. 1, pp. C25-C44.

- Artis M. J., Banerjee A., Marcellino M. (2005). Factor forecasts for the UK. Journal of Forecasting, Vol. 24, No. 4, pp. 27-298.

- Bańbura M., Rünstler G. (2011). A look into the factor model black box: publication lags and the role of hard and soft data in forecasting GDP. International Journal of Forecasting, Vol. 27, No. 2, pp. 333-346.

- Bernanke B. S., Boivin J. (2003). Monetary policy in a data-rich environment. Journal of Monetary Economics, Vol. 50, No. 3, pp. 525-546.

- Bernanke B. S., Boivin J., Eliasz P. (2005). Measuring the effects of monetary policy: a factor-augmented vector autoregressive (FAVAR) approach. Quarterly Journal of Economics, Vol. 120, No. 1, pp. 387-422.

- Boivin J., Ng S. (2005). Understanding and Comparing Factor-Based Forecasts. International Journal of Central Banking, Vol. 1, No. 3, pp. 117-151.

- Bragoli D., Metelli L., Modugno M. (2014). The Importance of Updating: Evidence from a Brazilian Nowcasting Model. Finance and Economics Discussion Series, No. 2014-94. Divisions of Research \& Statistics and Monetary Affairs, Federal Reserve Board, Washington, D.C.

- Brave S. A., Butters R. A. (2014). Nowcasting using the Chicago Fed National Activity Index. Economic Perspectives, Vol. 38, pp. 19-37.

- Breitung J., Eickmeier S. (2006). Dynamic Factor Models. Modern Econometric Analysis, pp. 25-40.

- Brisson M., Campbell B., Galbraith J. W. (2003). Forecasting Some Low-Predictability Time Series Using Diffusion Indices. Journal of Forecasting, Vol. 22, No. 6-7, pp. 515-531.

- Cristadoro R., Forni M., Reichlin L., Veronese G. (2001). A Core Inflation Index for the Euro Area. Working Papers, No. 435, Bank of Italy.

- Forni M., Giannone D., Lippi M., Reichlin L. (2004). Opening the black box: structural factor models vs structural VARs. Universite Libre de Bruxelles, mimeo.

- Forni M., Hallin M., Lippi M., Reichlin L. (2005). The generalized dynamic factor model: one-sided estimation and forecasting. Journal of the American Statistical Association, Vol. 100, No. 471, pp. 830-840.

- Giannone D., Reichlin L., Sala L. (2004). Monetary Policy in Real Time. NBER Macroeconomics Annual, Vol. 19, pp. 161-200.

- Giannone D., Reichlin L., Small D. (2008). Nowcasting: The real-time informational content of macroeconomic data. Journal of Monetary Economics, Vol. 55, No. 4, pp. 665-676.

- Giannone D., Reichlin L., Small D.H. (2006). Nowcasting GDP and inflation: the real-time informational content of macroeconomic data releases. Working Paper Series, No. 633, European Central Bank.

- Gupta R., Kabundi A., Ziramba E. (2010). The effect of defense spending on US output: a factor augmented vector autoregression (favar) approach. Defence and Peace Economics, Vol. 21, No. 2, pp. 135-147.

- Itkonen, J. (2016). How do we know where the economy is heading today? Bulletin Bank of Finland, Vol. 90, No. 3, pp. 51-61.

- Kaiser H. F. (1960). The application of electronic computers to factor analysis. Educational and psychological measurement, Vol. 20, No. 1, pp. 141-151.

- Kapetanios G. (2004). A note on modelling core inflation for the UK using a new dynamic factor estimation method and a large disaggregated price index dataset. Economics Letters, Vol. 85, No. 1, pp. 63-69.

- Lysenko R., Kolesnichenko N. (2016). Nowcasting of Economic Development Indicators Using the NBU's Business Survey Results. Visnyk of the National Bank of Ukraine, No. 235, pp. 43-56.

- Porshakov A., Deryugina E., Ponomarenko A. A., Sinyakov A. (2015). Nowcasting and short-term forecasting of Russian GDP with a dynamic factor model. Discussion Papers, No. 19/2015, BOFIT, Bank of Finland, pp. 4-40.

- Stock J. H., Watson M. W. (2002). Forecasting using principal components from a large number of predictors. Journal of the American statistical association, Vol. 97, No. 460, pp. 1167-1179.

- Stock J. H., Watson M. W. (2006). Forecasting with many predictors. Handbook of economic forecasting, Chapter 10, pp. 515-554.

- Stock J.H., Watson M. W. (1999). Forecasting inflation. Journal of Monetary Economics, Vol. 44, No. 2, pp. 293-335. 